\title{
Symmetric, Robust, and High-voltage Organic Redox Flow Battery Model Based on a Helical
}

\section{Carbenium Ion Electrolyte}

\author{
Jules Moutet, José M. Veleta and Thomas L. Gianetti* \\ Department of Chemistry and Biochemistry, The University of Arizona, Tucson, AZ 85721- \\ 0041, United States.
}

KEYWORDS: organic electrolyte, symmetric redox flow battery, helical carbenium, non-aqueous RFB.

ABSTRACT Redox flow batteries (RFBs) represent a promising technology for grid-scale integration of renewable energy. Redox-active molecular pairs with large potential windows have been identified as key components for these systems. However, cross-contamination problems encountered by the use of distinct catholyte and anolyte species still limits the development of reliable organic RFBs. Herein, we report the first use of a helical carbenium ion, with three stable oxidation states, as an electrolyte for the development of symmetric cells. Cyclic voltammoamperometric studies were conducted in acetonitrile to assess the essential kinetic properties for flow battery performance and cycling stability of this molecule. The stability of the [4]helicenium ion was then evaluated by mono-electronic cycling and bi-electronic stress experiments, resulting 
in 550 and 80 cycles respectively, with near-perfect capacity retention. This helical carbenium ionbased electrolyte achieved a proof-of-principle $2.12 \mathrm{~V}$ open circuit potential as an all-organic symmetric RFB.

Technological advances in renewable energy are progressively allowing our society to transition from fossil fuels to more sustainable energy sources. ${ }^{1}$ However, the development of efficient batteries, which store and redistribute the harvested energy in the grid, remains a key-challenge to be addressed..$^{2-4}$ The well-known high-performance lithium-ion batteries ${ }^{5}$ have proven to be a suitable solution, yet temporary since its availability is quickly being surpassed by civilian power needs.${ }^{67}$ In recent years, redox flow batteries (RFBs) have gained considerable attention to address the issues faced with large-scale storage of transient renewable energy. ${ }^{8-12}$ In RFBs, energy is stored in liquid electrolyte solutions which flow through an electrochemical cell during charge and discharge cycles. The "redox" term refers to the chemical reduction and oxidation reactions involved in the catholyte and anolyte that are converted to electrical power. Vanadium-based RFBs (VRFBs; Figure 1, purple box), ${ }^{10,13}$ as well as other metal-based electrolytes, ${ }^{14-17}$ possess high durability with an astounding cyclability of up to 20,000 cycles..$^{18}$ However, the use of transition metal ions is associated with their high cost and toxicity. ${ }^{19,20}$ In recent years, very promising organic-metal hybrid systems have emerged, ${ }^{17,21,22}$ yet these system to not address the need to freeing oneself from metal containing sytems. ${ }^{23}$ Redox-active organic materials (ROMs), and their applications in full organic RFBs, have thus emerged as an attractive alternative for low-cost and large-scale batteries due to their sustainable, synthetically tunable, and potentially inexpensive raw materials. ${ }^{24-28}$ Their development is of considerable interest for the scientific and engineering communities. ${ }^{29-31}$ 
The redox potential of ROMs, and the resulting open circuit voltage (OCV) between the electrolytes, is one of the most important properties since it determines the RFB voltage, and affects the energy density and power density provided. ${ }^{28}$ Recently, attractive OCV potential windows from 1.9 to $3.2 \mathrm{~V}$ have been reported for non-aqueous fully organic RFBs (ORFBs) (Figure 1, red box). ${ }^{32-34}$ Most of these ORFBs are asymmetric, since they are assembled by two chemically different redox-active pairs. While this allows easy tunability of the OCV, crossover contamination between catholyte and anolyte at the interface of the cell results in a loss of unrecoverable capacity, affecting the efficiency and durability of the battery. ${ }^{26,28}$ As a result, the best systems to date, show maximum cyclability values of 150 charge-discharge cycles while retaining their capacity (Figure 1, red box). ${ }^{34}$ The use of a single ROM as both anolyte and catholyte, in a so-called symmetric system, is believed to be key to improve the performance of ORFBs. In addition to preventing cross contamination, symmetric ORFBs can access three different oxidation states of the electrolyte within the same compartment, allowing the polarity to be reversed upon one-electron cycles. To date, only few examples of symmetric ORFBs have been reported, (Figure 1, green box), ${ }^{35-38}$ and these either possess a high OCV with low cyclability (Figure 1, examples iv, vii), or a better reliability (max of 100 cycles) but a small OCV (Figure $\mathbf{1}$, examples $\mathbf{v}$, vi). Yet these reports provide the pioneering evidence that symmetric ORFBs can open new junctures and lead to promising energy applications. 


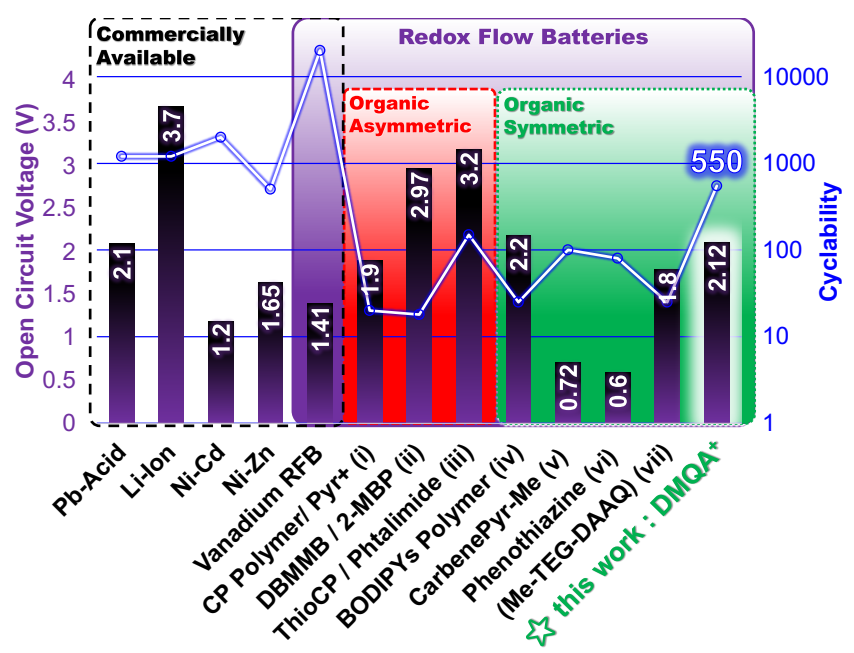

Figure 1: Open circuit voltage (OCV) feature for common batteries and recent promising RFBs $\left(\right.$ Cyclability $=$ initial capacity $\left(Q_{\text {init }}\right)$ retention $\geq 90 \%$ after $n$ cycles $)$ with their electrolyte couples: (i) $,{ }^{32}(\mathbf{i i}),{ }^{33}($ iii $),{ }^{34}$ (iv) $,{ }^{35}(\mathbf{v}),{ }^{36}(\mathbf{v i}),{ }^{37}$ (vii) ${ }^{38}$

Recently, a family of helical carbenium ions, namely dimethoxyquinacridiniums (DMQA ${ }^{+}$), has received increasing interest due to their photophysical, electrochemical, and biological properties. ${ }^{39-42}$ Noticeably, the Laursen and Lacour groups reported the reversible electrochemical oxidation and reduction events of these stable carbenium ions. ${ }^{43,44}$ Similarly, our group recently reported the chemical reduction of a series of these cations leading to the isolation and characterization of the corresponding neutral radical analog (DMQA $).{ }^{45}$ We also demonstrated that the helicene $\left[{ }^{n} \mathrm{Pr}-\mathrm{DMQA}\right]\left[\mathrm{BF}_{4}\right]$ salt $\left(\mathbf{C}^{+}\right.$, Figure $\left.\mathbf{2 a}\right)$ is an efficient photocatalyst undergoing both chemical reduction and oxidation reactions via single-electron transfer. ${ }^{46}$ Yet, the use of these redox-active compounds has never been reported in electrochemical and energy storage applications. These helical carbenium ions are uniquely well-suited for RFB due to their rapid modular synthesis, electrochemical stability to wide voltage windows, and the accessibility of several oxidation states. Herein, we report the electrochemical study of $\mathbf{C}^{+}$as both anolyte and 
catholyte for the development of a symmetrical non-aqueous ORFB, with a remarkable OCV of more than $2.1 \mathrm{~V}$ and retaining more than $90 \%$ of its initial capacity after 550 cycles.

Previous reports showed that $\mathbf{C}^{+}$can be electrochemically reduced by one electron to form the neutral radical $\mathbf{C}^{\bullet}$ and oxidized by one electron to form the radical dication $\mathbf{C}^{\bullet++}$ (Figure 2a) ${ }^{43-45}$ However, if these species are to be used for battery purposes, they must possess high stability during storage, charge, and discharge processes over extended periods of time in the solvent of choice. ${ }^{28}$ We previously reported that the electrochemical behavior of $\mathbf{C}^{+}$in dichloromethane showed that the reduced and oxidized species were electrochemically reversible, but the stability of the reduced species $\left(\mathbf{C}^{\bullet}\right)$ was limited to a few minutes ${ }^{45}$ Cyclic voltammetry $(\mathrm{CV})$ experiments in DMF showed higher stability of the $\mathbf{C}^{\bullet}$ species, but poor reversibility was observed for the $\mathbf{C}^{\bullet++}$ radical (Figure S1). ${ }^{1}$ Finally good reversibility and stability for both redox species of $\mathbf{C}^{+}$was observed by CV in acetonitrile (Figure $\mathbf{2 b}$ and S2). ${ }^{44}$ Differential pulse voltammetry (DPV) showed that the redox events occurs at $\mathrm{E}_{1 / 2 \mathrm{red}}=-1.14 \mathrm{~V}$ process and $\mathrm{E}_{1 / 2 \mathrm{ox}}=+0.98 \mathrm{~V}$ in acetonitrile (Figure S3) ${ }^{44}$ The measured OCV between these processes was found to be $2.12 \mathrm{~V}$, which supports its potential application as a high-voltage and symmetric ORFB (Figure 2b).

\footnotetext{
${ }^{1}$ To facilitate comparison, all electrochemical measurements are presented in $\mathrm{V}$ vs the reference $\mathrm{AgNO}_{3} / \mathrm{Ag}$ couple $\left(E_{\text {Ref }}\right)$. Through-out this paper, the numbers reported in parentheses indicate the standard deviation in the last reported digit.
} 

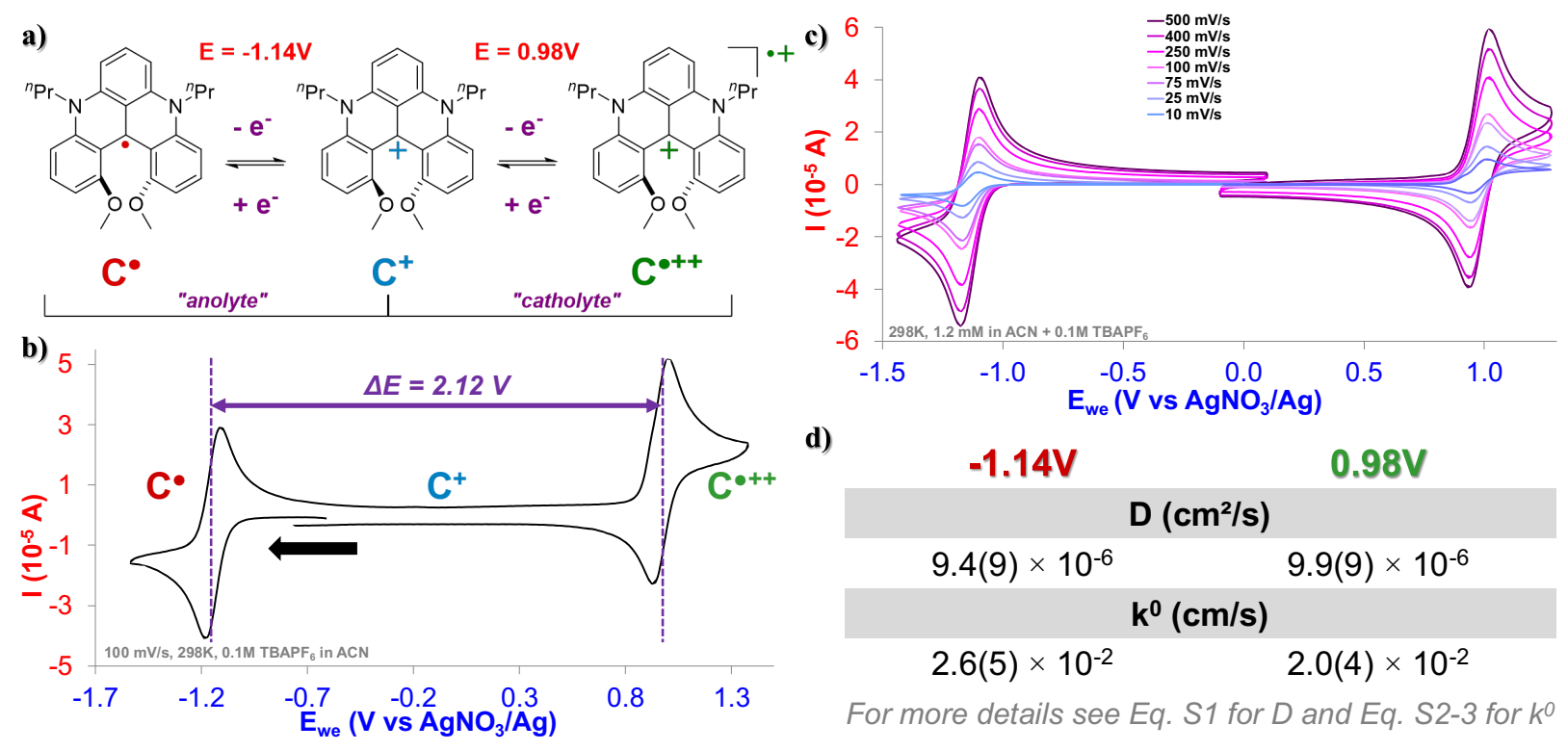

Figure 2: a) Scheme of redox processes for $\mathbf{C}^{+}$. b) $\mathrm{CV}$ at scan rate of $100 \mathrm{mV} \mathrm{s}^{-1}$ and c) Independents CVs at various scan rate $\left(10\right.$ to $\left.500 \mathrm{mV} \mathrm{s}^{-1}\right)$ of the electronic processes for a $1.2 \mathrm{mM}$ solution of $\mathbf{C}^{+}$in $0.1 \mathrm{M} \mathrm{TBAPF}_{6} /$ acetonitrile $(\mathrm{ACN})$. d) $D$ and $k^{0}$ were determined by studying CVs at different scan rates from 10 to $500 \mathrm{mV} / \mathrm{s}$.

The reversibility of the redox events of $\mathbf{C}^{+}$was further investigated by acquisition of CVs at different scan rates (Figure $2 \mathbf{c}$ and $\mathbf{S 4}$ ). The measured intensity $\left(\mathrm{i}_{\mathrm{p}}\right)$ reported as a function of the square root of the scan rate exhibits a linear relation (Figure S5), indicating analyte diffusion from the electrodes and reversibility of the redox processes at each scan rate. Based on these plots, the essential electrochemical kinetics parameters for this ROM were also extracted (Figure 2d). Using the Randles-Sevcik equation (Equation S1), an experimental diffusion coefficient $(D)$ of 9.4(9) $\times$ $10^{-6} \mathrm{~cm}^{2} \mathrm{~s}^{-1}$ and $9.9(9) \times 10^{-6} \mathrm{~cm}^{2} \mathrm{~s}^{-1}$ were determined for the $\mathbf{C}^{+} / \mathbf{C}^{\bullet}$ and $\mathbf{C}^{\bullet++} / \mathbf{C}^{+}$couples, respectively. These values are higher than other known anolytes, ${ }^{33,47,48}$ and about three times higher than recent catholytes studied, which is an advantage for our DMQA ${ }^{+32-34,48,49}$ The electron transfer rate constants $\left(k^{0}\right)$ were determined using the improved Nicholson's method (Equation S2-S3, 
Table S4), ${ }^{50,51}$ where the $k^{0}=2.6(5) \times 10^{-2} \mathrm{~cm} \mathrm{~s}^{-1}$ for $\mathbf{C}^{+} / \mathbf{C}^{\bullet}$ redox couple is almost similar to that of the $\mathbf{C}^{\bullet++} / \mathbf{C}^{+}$redox pair $k^{0}=2.0(4) \times 10^{-2} \mathrm{~cm} \mathrm{~s}^{-1}$ and both are higher to recent electrolytes developed for RFB..$^{32,34}$ The persistent oxidized and reduced species of $\mathbf{C}^{+}$, and their fast and close electronic kinetics, suggest that this electrolyte is suitable for ORFB application.

We then investigated the use of this [4]helical carbocation as an electrolyte for a symmetric ORFB application. The saturation concentration of the $\mathbf{C}^{+}$salt in pure acetonitrile was evaluated at 32.4 $\pm 0.1 \mathrm{mM}$ by UV-Visible via a calibration curve (Figure S6-S7). The electrochemical stability of the electrolyte $\mathbf{C}^{+}$was evaluated by bulk electrolysis charge/discharge cycling using a threeelectrode cell modelling a redox flow cell setup. Sanford et al. have shown that similar electrochemical cell designs with organic ROMs have been acceptable test beds for RFBs performance. ${ }^{32}$ Charge-discharge experiments were performed inside a nitrogen-filled glovebox with a setup inspired by Hansmann et al. ${ }^{35}$ using a custom-made H-cell with a porous glass frit to separate both compartments. The reference electrode (0.01 $\mathrm{M} \mathrm{AgNO}_{3} / \mathrm{Ag}$ in $0.1 \mathrm{M} \mathrm{TBAPF}_{6} / \mathrm{ACN}$ solution) with two reticulated vitreous carbon (RVC) electrodes (Duocel ${ }^{\circledR}, 100$ ppi) were added to complete our test cell (Figure S8-S9). Both sides of the cell were equally filled with a $1.2 \mathrm{mM}$ solution of $\mathbf{C}^{+}(0.1 \mathrm{M}$ TBAPF$/ \mathrm{ACN})$ (Figure 3a, "Init."). 


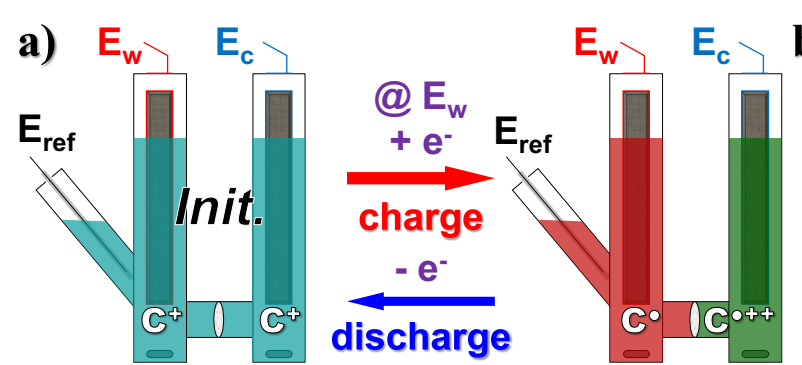

c)

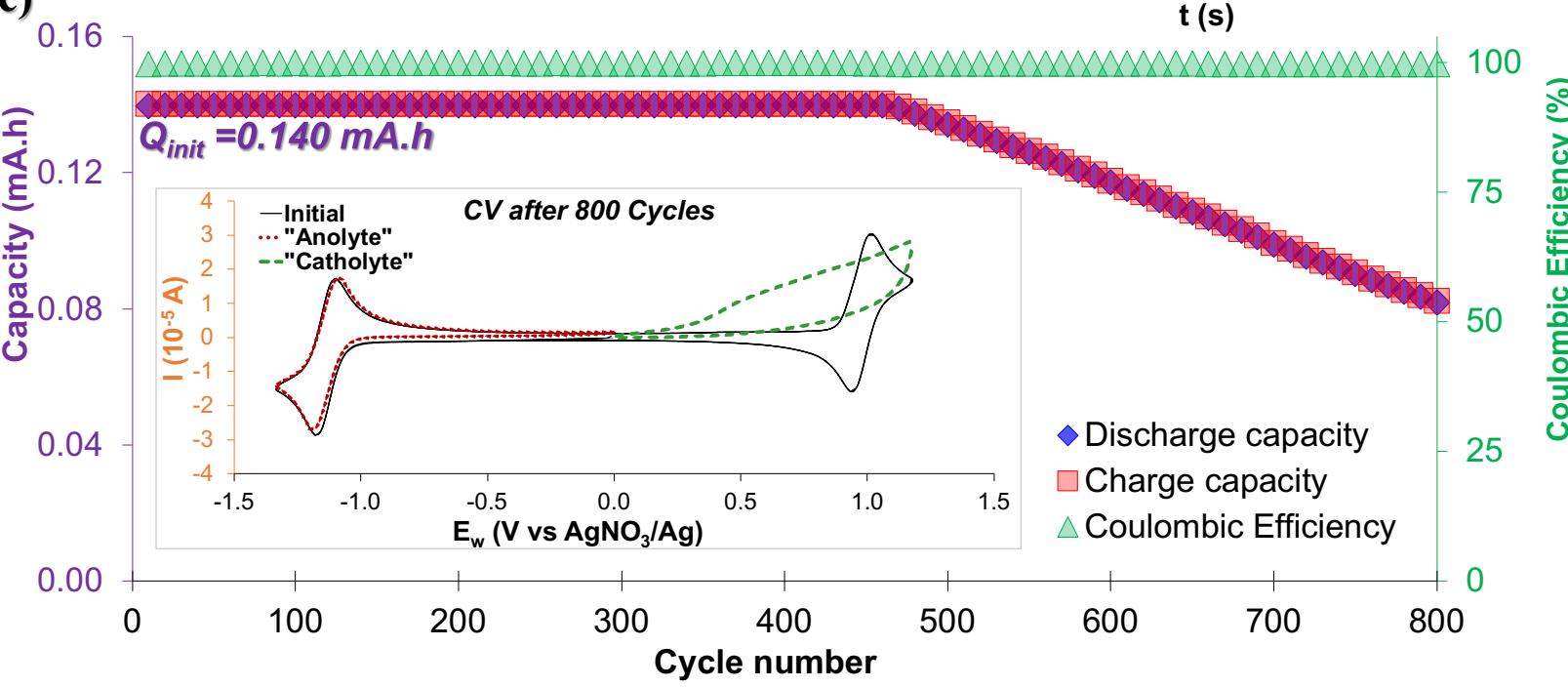

Figure 3: a) Scheme showing the mono- electronic charge-discharge cycles in a symmetric $\mathrm{H}$-cell. The color code is indicative of the electrolyte oxidation degree and corresponds to the colors observed by the operator. b) Zoom-in of $\mathrm{E}_{\mathrm{we}}$ along the $25^{\text {th }}$ to $35^{\text {th }}$ cycles of cycling and species formation in $\mathrm{E}_{\mathrm{ref}}$ compartment. c) $Q$ of charge-discharge processes and coulombic efficiency monitoring over 800 cycles of mono-electronic exchange (for better readability, 1 dot every 10 cycles). Inset shows $\mathrm{CV}$ analysis at $100 \mathrm{mV} / \mathrm{s}$ of the respective contents of each side of the cell after 800 cycles.

In the first instance, mono-electron transfer at $90 \%$ theoretical capacity (90\% State Of Charge "SOC") charge and discharge cycles (Figure 3a) were performed with a Constant Current following by a Constant Voltage galvanostatic charging (CCCV GCPL protocol) of $15 \mid \mathrm{mA}$ with potentials boundaries at $-1.54 \mathrm{~V}$ and $-0.64 \mathrm{~V}$ vs $\mathrm{E}_{\text {ref }}$. A complete cycle corresponds to a charge step 
followed by a discharge step (Figure 3b). During the charge-discharge cycles a plateau at c.a. -1.1 $\mathrm{V}$ in $\mathrm{E}_{\mathrm{w}}$ voltage curves was noted and assigned to the electronic process of $\mathbf{C}^{+} / \mathbf{C}^{\bullet}$ redox couple (Figure S10). Extremely satisfactorily, the monitoring of this test cell in Figure 3c, shows that the coulombic efficiency (CE, green triangle) remains constant and close to $100 \%$ throughout the experiment. Furthermore, the capacity $Q$ (red and blue squares) has proven to be excellent, with an initial Capacity $\left(\mathrm{Q}_{\text {init }}\right)$ retention $>90 \%$ over 550 cycles (Figures 3c, S11 $-\mathbf{S 1 2}$ ). The decrease in the capacity of our battery started at the $461^{\text {th }}$ cycle. Then the system lost $0.16 \%$ of capacity retention per cycle, reaching a value of $\mathrm{Q}=0.081 \mathrm{~mA} . \mathrm{h}$ at the $800^{\text {th }}$ cycle when the battery was stopped (i.e. $58 \%$ of the $\mathrm{Q}_{\text {init }}$ ). After the $800^{\text {th }}$ cycle, a CV analysis at $100 \mathrm{mV} / \mathrm{s}$ of the respective contents of each side of the cell was performed (Figure 3c Inset, and S13). It was found that the use of $\mathbf{C}^{+}$as an "anolyte" is particularly robust and reliable with an appearance that can be superimposed on the initial CV. However, the CV of the "catholyte" compartment shows a loss of resolution of the phenomenon in oxidation. This is correlated with the appearance of a light deposit on the RVC electrode, suggesting that the solubility of the $\mathbf{C}^{\bullet++}$ species is a limiting factor of this system. We assume that the loss of ROM by precipitation in the cathode compartment induces the loss of capacity noted in Figure 3c. Nevertheless, the remarkable values obtained underline the stability of our battery model, which was ran over $88.7 \mathrm{~h}$, as well as its ability to deliver the stored energy efficiently.

In "classical" ORFB, the overall system is asymmetric, meaning one side of the cell containing the "anolyte" and the other containing the "catholyte" and must therefore always be polarized in the same way to work. ${ }^{10,32}$ However, the electronic properties of $\mathbf{C}^{+}$allow us to overcome this limitation, since the system can be charged independently by transferring electrons into one or the other side of the cell. Therefore, it is possible to carry out bi-electronic cycling tests by polarizing 
the battery in the opposite direction. This protocol consists of a highly stressful two-electron charge and discharge process on each side of the cell at 100\% SOC. This meaning that the species $\mathbf{C}^{\bullet++}$ and $\mathbf{C}^{\bullet}$ will be formed successively in each compartment over time (Figure 4a). These twoelectron cycling processes, labeled "stress-test", are likely to shorten the life of the battery and are not meant to describe the energy storage ability of our electrolyte under these conditions. ${ }^{35,52}$ The experiment will however provide insightful information about the sturdiness of the battery.
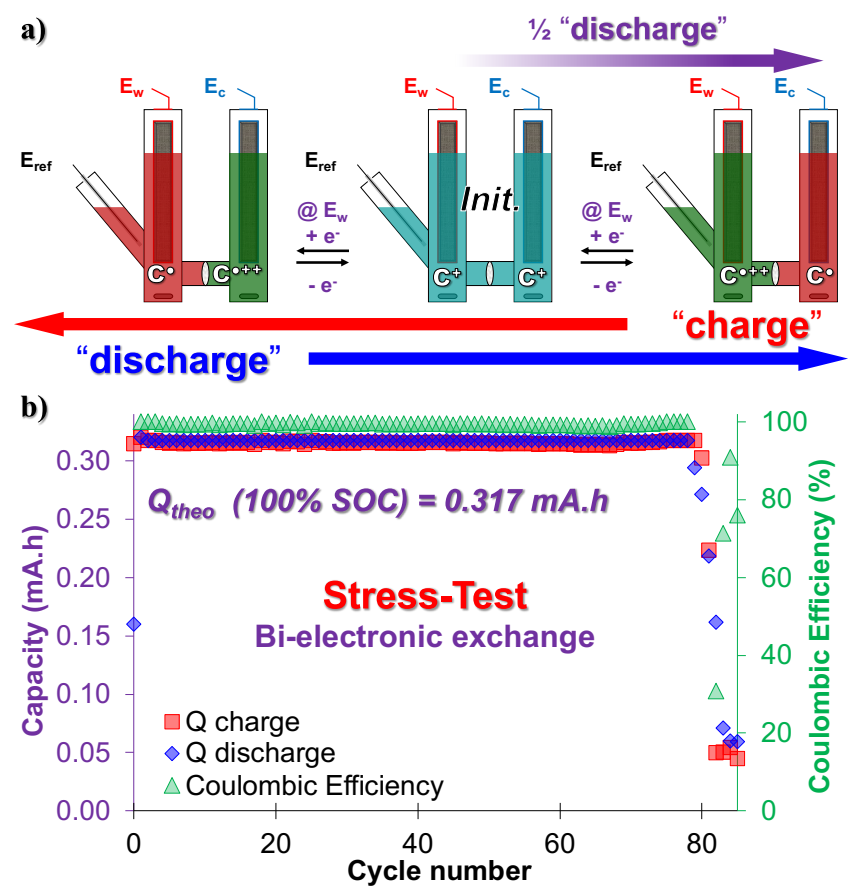

Figure 4: a) Scheme showing the bi-electronic charge-discharge cycles in a symmetric H-cell as stress-test. The color code is indicative of the electrolyte oxidation degree and corresponds to the colors observed by the operator. b) $Q$ of charge-discharge processes and coulombic efficiency monitoring over 85 cycles of bi-electronic exchange.

A CCCV galvanostatic charging sequence with a $151 \mathrm{~mA}$ current, setting potentials boundaries at 1.38 and $-1.54 \mathrm{~V}$ vs. $\mathrm{E}_{\text {ref, }}$, was then started from initial state of this symmetrical battery (Figure 
4a). In the first step, the working electrode side of the cell was discharged of electrons at a cutoff potential of $1.38 \mathrm{~V}$ to full oxidation of $\mathbf{C}^{+}$to $\mathbf{C}^{\bullet++}$ (Figure 4a, purple arrow). Then a negative 5 $\mathrm{mA}$ current was applied at $-1.54 \mathrm{~V}$ (red arrow), and two electrons were sequentially exchanged taking $\mathbf{C}^{\bullet++}$ to $\mathbf{C}^{\bullet}$. Finally, the current was reversed to $1.38 \mathrm{~V}$ to discharge the electrons in the working electrode side of the cell back to $\mathbf{C}^{\bullet++}$ (blue arrow). The continuous alternation of steps red and blue corresponded to a cycle. Interestingly, during the electron charge/discharge cycles two plateaus at c.a. $-1.1 \mathrm{~V}$ and $0.9 \mathrm{~V}$ in $\mathrm{E}_{\mathrm{w}}$ voltage curves were observed, in agreement with the processes recorded in the CV (Figure S16). During the experiment, the threshold value of $-1.54 \mathrm{~V}$ in discharge was reached, however the $1.38 \mathrm{~V}$ threshold was slowly reached over the $81^{\text {st }}$ cycle (Figure S17). Concurrently, this phenomenon can be compared to the CE of the battery. The efficiency was calculated based on the overall cell capacity, or $Q$ for charge/discharge of $Q_{\text {theo }}=$ 0.317 mA.h (Figure 3b). As shown by the green trace, the CE was almost constant and close to $100 \%$ until the $80^{\text {th }}$ cycle, with a quasi-constant full capacity $Q=Q_{\text {theo }}$ for two-electrons cycling. Then a drastic drop in $Q$ discharge with an irrecoverable capacity loss of $84 \%$ between cycles 80 and 83 was observed. This corresponded to a decrease in CE in the $82^{\text {nd }}$ cycle and suggested the end of our system's life, presumably due to electrolyte fatigue when it is in its $\mathbf{C}^{\bullet++}$ form. Current efforts consist in improving the stability of the oxidation process over time, and rationalizing its decay to improve the properties of this [4]helical cation.

In summary, we report a new high-potential organic electrolyte for nonaqueous RFBs. Through an in-depth study of the electronic characteristics of the selected carbenium ion, we have highlighted the reversibility of two redox processes with a large potential gap. The stability of the neutral radical $\left(\mathbf{C}^{\cdot}\right)$ and radical dication $\left(\mathbf{C}^{\cdot++}\right)$ forms of ${ }^{n} \operatorname{Pr}-\mathrm{DMQA}^{+}\left(\mathbf{C}^{+}\right)$in acetonitrile was demonstrated. The analysis of fundamental electrochemical kinetic properties allowed us to evaluate the behavior 
of this molecule within an H-cell, as an ORFB model. This work enabled the realization of the best performing high voltage non-aqueous all-organic symmetrical flow battery model to date. In single-electronic operating mode, the cell can reach more than 550 charge/discharge cycles with excellent $Q$ retention and CE for a 2.12V OCV. Meanwhile, two-electron charge/discharge stressexperiments showed the robustness and high reliability of this electrolyte beyond $15 \mathrm{~h}$ of continuous electrochemical stress, showing excellent CE and almost $100 \%$ capacity retention over 80 cycles. This [4]helicenium core is a promising new class of electrolyte for the development of high-performance symmetrical ORFBs. 


\section{ASSOCIATED CONTENT}

Supporting Information. A listing of the contents of each file supplied as Supporting Information should be included.

\section{AUTHOR INFORMATION}

\section{Corresponding Author}

Thomas L. Gianetti - ORCID 0000-0002-3892-3893- University of Arizona, Department of Chemistry and Biochemistry, Tucson, Arizona, United States; tgianetti@arizona.edu; https://www.gianettigroup.com; @ gianettigroup

\section{Author Contributions}

The manuscript was written through contributions of all authors. All authors have given approval to the final version of the manuscript. JM conducted all experiments, TLG and JM wrote the manuscript, plan the experiments and discussed their conclusions.

\section{Funding Sources}

We are grateful for the financial support from the University of Arizona.

\section{Notes}

The authors declare no competing financial interest.

\section{ACKNOWLEDGMENT}

We thank Profs. Pyun and Lichtenberger from the University of Arizona for helpful discussions.

We thank Rajeswari Das from the University of Arizona for her contribution in the solubility 
analysis. Dr. JM is grateful to Dr. Vincent Caldeira from Grenoble INP-LEPMI/EasylSA for helpful discussions.

\section{REFERENCES}

(1) Dresselhaus, M. S.; Thomas, I. L. Alternative Energy Technologies. Nature 2001, 414 (6861), 332-337.

(2) Yang, Z.; Zhang, J.; Kintner-Meyer, M. C. W.; Lu, X.; Choi, D.; Lemmon, J. P.; Liu, J. Electrochemical Energy Storage for Green Grid. Chem. Rev. 2011, 111 (5), 3577-3613.

(3) Badwal, S. P. S.; Giddey, S. S.; Munnings, C.; Bhatt, A. I.; Hollenkamp, A. F. Emerging Electrochemical Energy Conversion and Storage Technologies. Front. Chem. 2014, 2 (September), 1-28.

(4) Gür, T. M. Review of Electrical Energy Storage Technologies, Materials and Systems: Challenges and Prospects for Large-Scale Grid Storage. Energy Environ. Sci. 2018, 11 (10), 2696-2767.

(5) Goodenough, J. B.; Whittingham, M. S.; Yoshino, A. The Nobel Prize in Chemistry 2019 "for the Development of Lithium-Ion Batteries." R. Swedish Acad. Sci. 2019, https://www.nobelprize.org/prizes/chemistry/2019/p.

(6) Tarascon, J.-M.; Armand, M. Issues and Challenges Facing Rechargeable Lithium Batteries. Nature 2001, 414 (6861), 359-367.

(7) Winter, M.; Barnett, B.; Xu, K. Before Li Ion Batteries. Chem. Rev. 2018, 118 (23), 1143311456. 
(8) Leung, P.; Li, X.; Ponce de León, C.; Berlouis, L.; Low, C. T. J.; Walsh, F. C. Progress in Redox Flow Batteries, Remaining Challenges and Their Applications in Energy Storage. RSC Adv. 2012, 2 (27), 10125-10156.

(9) Rugolo, J.; Aziz, M. J. Electricity Storage for Intermittent Renewable Sources. Energy Environ. Sci. 2012, 5 (5), 7151-7160.

(10) Soloveichik, G. L. Flow Batteries: Current Status and Trends. Chem. Rev. 2015, 115 (20), $11533-11558$.

(11) Park, M.; Ryu, J.; Wang, W.; Cho, J. Material Design and Engineering of Next-Generation Flow-Battery Technologies. Nat. Rev. Mater. 2017, 2, 16080.

(12) Kwabi, D. G.; Ji, Y.; Aziz, M. J. Electrolyte Lifetime in Aqueous Organic Redox Flow Batteries: A Critical Review. Chem.Rev. 2020, acs.chemrev.9b00599.

(13) Lu, W.; Li, X.; Zhang, H. The next Generation Vanadium Flow Batteries with High Power Density-A Perspective. Phys. Chem. Chem. Phys. 2017, 20 (1), 23-35.

(14) Wang, W.; Kim, S.; Chen, B.; Nie, Z.; Zhang, J.; Xia, G.-G.; Li, L.; Yang, Z. A New Redox Flow Battery Using Fe/V Redox Couples in Chloride Supporting Electrolyte. Energy Environ. Sci. 2011, 4 (10), 4068-4073.

(15) Cabrera, P. J.; Yang, X.; Suttil, J. A.; Hawthorne, K. L.; Brooner, R. E. M.; Sanford, M. S.; Thompson, L. T. Complexes Containing Redox Noninnocent Ligands for Symmetric, Multielectron Transfer Nonaqueous Redox Flow Batteries. J. Phys. Chem. C 2015, 119 (28), 15882-15889. 
(16) Gandomi, Y. A.; Aaron, D. S.; Houser, J. R.; Daugherty, M. C.; Clement, J. T.; Pezeshki, A. M.; Ertugrul, T. Y.; Moseley, D. P.; Mench, M. M. Critical Review-Experimental Diagnostics and Material Characterization Techniques Used on Redox Flow Batteries. J. Electrochem. Soc. 2018, 165 (5), A970-A1010.

(17) Park, M.; Beh, E. S.; Fell, E. M.; Jing, Y.; Kerr, E. F.; Porcellinis, D.; Goulet, M.; Ryu, J.; Wong, A. A.; Gordon, R. G.; Cho, J.; Aziz, M. J. A High Voltage Aqueous Zinc-Organic Hybrid Flow Battery. Adv. Energy Mater. 2019, 9 (25), 1900694.

(18) Ding, C.; Zhang, H.; Li, X.; Liu, T.; Xing, F. Vanadium Flow Battery for Energy Storage: Prospects and Challenges. J. Phys. Chem. Lett. 2013, 4 (8), 1281-1294.

(19) DOE Office of ARPR-E. ARPA-E. GRIDS Program Overview https://arpae.energy.gov/sites/default/files/documents/files/GRIDS_ProgramOverview.pdf.

(20) U.S. DEPARTMENT OF HEALTH AND HUMAN SERVICES Public Health Service Agency for Toxic Substances and Disease Registry. Toxicological Profile for Vanadium. In ATSDR's Toxicological Profiles; CRC Press, 2012.

(21) Ding, Y.; Zhang, C.; Zhang, L.; Zhou, Y.; Yu, G. Pathways to Widespread Applications: Development of Redox Flow Batteries Based on New Chemistries. Chem 2019, 5 (8), 19641987.

(22) Zhang, L.; Qian, Y.; Feng, R.; Ding, Y.; Zu, X.; Zhang, C.; Guo, X.; Wang, W.; Yu, G. Reversible Redox Chemistry in Azobenzene-Based Organic Molecules for High-Capacity and Long-Life Nonaqueous Redox Flow Batteries. Nat. Commun. 2020, 11 (1), 3843.

Chen, R.; Bresser, D.; Saraf, M.; Gerlach, P.; Balducci, A.; Kunz, S.; Schröder, D.; 
Passerini, S.; Chen, J. A Comparative Review of Electrolytes for Organic-Material-Based Energy-Storage Devices Employing Solid Electrodes and Redox Fluids. ChemSusChem 2020, 13 (9), 2205-2219.

(24) Schon, T. B.; McAllister, B. T.; Li, P.-F.; Seferos, D. S. The Rise of Organic Electrode Materials for Energy Storage. Chem. Soc. Rev. 2016, 45 (22), 6345-6404.

(25) Winsberg, J.; Hagemann, T.; Janoschka, T.; Hager, M. D.; Schubert, U. S. Redox-Flow Batteries: From Metals to Organic Redox-Active Materials. Angew. Chemie - Int. Ed. 2017, $56(3), 686-711$.

(26) Wei, X.; Pan, W.; Duan, W.; Hollas, A.; Yang, Z.; Li, B.; Nie, Z.; Liu, J.; Reed, D.; Wang, W.; Sprenkle, V. Materials and Systems for Organic Redox Flow Batteries: Status and Challenges. ACS Energy Lett. 2017, 2 (9), 2187-2204.

(27) Ding, Y.; Zhang, C.; Zhang, L.; Zhou, Y.; Yu, G. Molecular Engineering of Organic Electroactive Materials for Redox Flow Batteries. Chem. Soc. Rev. 2018, 47 (1), 69-103.

(28) Luo, J.; Hu, B.; Hu, M.; Zhao, Y.; Liu, T. L. Status and Prospects of Organic Redox Flow Batteries toward Sustainable Energy Storage. ACS Energy Lett. 2019, 4 (9), 2220-2240.

(29) Janoschka, T.; Martin, N.; Martin, U.; Friebe, C.; Morgenstern, S.; Hiller, H.; Hager, M. D.; Schubert, U. S. An Aqueous, Polymer-Based Redox-Flow Battery Using Non-Corrosive, Safe, and Low-Cost Materials. Nature 2015, 527 (7576), 78-81.

(30) Lin, K.; Chen, Q.; Gerhardt, M. R.; Tong, L.; Kim, S. B.; Eisenach, L.; Valle, A. W.; Hardee, D.; Gordon, R. G.; Aziz, M. J.; Marshak, M. P. Alkaline Quinone Flow Battery. Science 2015, 349 (6255), 1529-1532. 
(31) Service, R. F. Advances in Flow Batteries Promise Cheap Backup Power. Science 2018, 362 (6414), 508-509.

(32) Hendriks, K. H.; Robinson, S. G.; Braten, M. N.; Sevov, C. S.; Helms, B. A.; Sigman, M. S.; Minteer, S. D.; Sanford, M. S. High-Performance Oligomeric Catholytes for Effective Macromolecular Separation in Nonaqueous Redox Flow Batteries. ACS Cent. Sci. 2018, 4 (2), 189-196.

(33) Xing, X.; Liu, Q.; Xu, W.; Liang, W.; Liu, J.; Wang, B.; Lemmon, J. P. All-Liquid Electroactive Materials for High Energy Density Organic Flow Battery. ACS Appl.Energy Mater. 2019, 2 (4), 2364-2369.

(34) Yan, Y.; Robinson, S. G.; Sigman, M. S.; Sanford, M. S. Mechanism-Based Design of a High-Potential Catholyte Enables a 3.2 V All-Organic Nonaqueous Redox Flow Battery. J . Am. Chem. Soc. 2019, 141 (38), 15301-15306.

(35) Antoni, P. W.; Bruckhoff, T.; Hansmann, M. M. Organic Redox Systems Based on Pyridinium-Carbene Hybrids. J. Am. Chem. Soc. 2019, 141 (24), 9701-9711.

(36) Winsberg, J.; Hagemann, T.; Muench, S.; Friebe, C.; Häupler, B.; Janoschka, T.; Morgenstern, S.; Hager, M. D.; Schubert, U. S. Poly(Boron-Dipyrromethene)-A RedoxActive Polymer Class for Polymer Redox-Flow Batteries. Chem. Mater. 2016, 28 (10), 3401-3405.

(37) Attanayake, N. H.; Kowalski, J. A.; Greco, K. V.; Casselman, M. D.; Milshtein, J. D.; Chapman, S. J.; Parkin, S. R.; Brushett, F. R.; Odom, S. A. Tailoring Two-ElectronDonating Phenothiazines To Enable High-Concentration Redox Electrolytes for Use in 
Nonaqueous Redox Flow Batteries. Chem. Mater. 2019, 31 (12), 4353-4363.

(38) Geysens, P.; Li, Y.; Vankelecom, I.; Fransaer, J.; Binnemans, K. Highly Soluble 1,4Diaminoanthraquinone Derivative for Nonaqueous Symmetric Redox Flow Batteries. ACS Sustain. Chem. Eng. 2020, 8 (9), 3832-3843.

(39) Laleu, B.; Mobian, P.; Herse, C.; Laursen, B. W.; Hopfgartner, G.; Bernardinelli, G.; Lacour, J. Resolution of [4]Heterohelicenium Dyes with Unprecedented Pummerer-like Chemistry. Angew. Chemie Int. Ed. 2005, 44 (12), 1879-1883.

(40) Mobian, P.; Nicolas, C.; Francotte, E.; Bürgi, T.; Lacour, J. Synthesis, Resolution, and VCD Analysis of an Enantiopure Diazaoxatricornan Derivative. J. Am. Chem. Soc. 2008, 130 (20), 6507-6514.

(41) Bosson, J.; Gouin, J.; Lacour, J. Cationic Triangulenes and Helicenes: Synthesis, Chemical Stability, Optical Properties and Extended Applications of These Unusual Dyes. Chem. Soc. Rev. 2014, 43 (8), 2824-2840.

Delgado, I. H.; Pascal, S.; Wallabregue, A.; Duwald, R.; Besnard, C.; Guénée, L.; Nançoz, C.; Vauthey, E.; Tovar, R. C.; Lunkley, J. L.; Muller, G.; Lacour, J. Functionalized Cationic [4]Helicenes with Unique Tuning of Absorption, Fluorescence and Chiroptical Properties up to the Far-Red Range. Chem. Sci. 2016, 7 (7), 4685-4693.

(43) Herse, C.; Bas, D.; Krebs, F. C.; Bürgi, T.; Weber, J.; Wesolowski, T.; Laursen, B. W.; Lacour, J. A Highly Configurationally Stable [4]Heterohelicenium Cation. Angew. Chemie Int. Ed. 2003, 42 (27), 3162-3166.

(44) Sørensen, T. J.; Nielsen, M. F.; Laursen, B. W. Synthesis and Stability of N,N'-Dialkyl- 
1,13-Dimethoxyquinacridinium (DMQA+): A [4]Helicene with Multiple Redox States. Chempluschem 2014, 79 (7), 1030-1035.

(45) Shaikh, A. C.; Hossain, M.; Moutet, J.; Veleta, J. M.; Bloch, J.; Andrei, V. Stable Helicenium Radicals: Synthesis, Structure, Optical Properties, and Photocatalysis. ChemRxiv 2020, No. DOI: 10.26434/chemrxiv.12408245.v1., submitted.

(46) Mei, L.; Veleta, J. M.; Gianetti, T. L. Helical Carbenium Ion: A Versatile Organic Photoredox Catalyst for Red-Light-Mediated Reactions. J. Am. Chem. Soc. 2020, 142 (28), 12056-12061.

(47) Huskinson, B.; Marshak, M. P.; Suh, C.; Er, S.; Gerhardt, M. R.; Galvin, C. J.; Chen, X.; Aspuru-Guzik, A.; Gordon, R. G.; Aziz, M. J. A Metal-Free Organic-Inorganic Aqueous Flow Battery. Nature 2014, 505 (7482), 195-198.

(48) Wei, X.; Duan, W.; Huang, J.; Zhang, L.; Li, B.; Reed, D.; Xu, W.; Sprenkle, V.; Wang, W. A High-Current, Stable Nonaqueous Organic Redox Flow Battery. ACS Energy Lett. 2016, $1(4), 705-711$.

(49) Yu, X.; Manthiram, A. A Strategically Managed Rechargeable Battery System with a Neutral Methyl Viologen Anolyte and an Acidic Air-Cathode Enabled by a Mediator-Ion Solid Electrolyte. Sustain. Energy Fuels 2018, 2 (7), 1452-1457.

(50) Nicholson, R. S. Theory and Application of Cyclic Voltammetry for Measurement of Electrode Reaction Kinetics. Anal. Chem. 1965, 37 (11), 1351-1355.

(51) Lavagnini, I.; Antiochia, R.; Magno, F. An Extended Method for the Practical Evaluation of the Standard Rate Constant from Cyclic Voltammetric Data. Electroanalysis 2004, 16 
(6), 505-506.

(52) Hendriks, K. H.; Sevov, C. S.; Cook, M. E.; Sanford, M. S. Multielectron Cycling of a LowPotential Anolyte in Alkali Metal Electrolytes for Nonaqueous Redox Flow Batteries. ACS Energy Lett. 2017, 2 (10), 2430-2435.

\section{Table of Content}

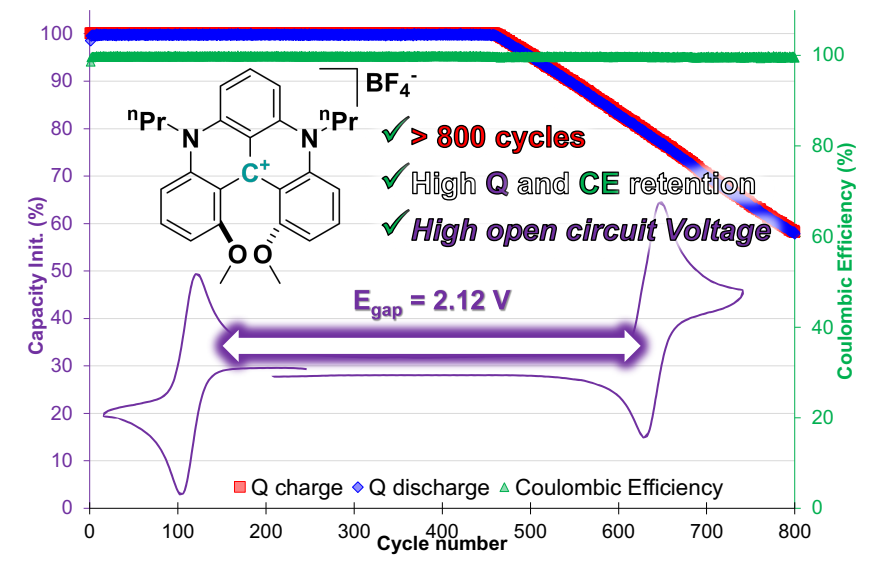

